\title{
ECONOMICS AND REMEDIAL PROCESSES DURING BROWNFIELD REDEVELOPMENT FROM THEORY TO PRACTICE: EXAMPLES FROM THE CZECH REPUBLIC
}

\author{
S. ČIHÁKOVÁ AGUILAR ${ }^{1}$, M. ČERNÍKOVÁ ${ }^{2}$ \\ ${ }^{1}$ Institute of Novel Technologies and Applied Informatics, \\ Technical University in Liberec, \\ Czech Republic. \\ ${ }^{2}$ Faculty of Economics, Technical University of Liberec, \\ Czech Republic.
}

\begin{abstract}
Since the end of the 1980s, the Czech Republic has faced difficult times in the area of improvement of the living environment. The former socialistic regime originated some of the worst environmental indicators in Europe. Although the state of the environment in the Czech Republic has improved, it is still necessary to ensure a good quality in some particular areas. One of them is the management of depressed areas (Brownfields). The scope of this work is to describe how various schools of economics focus their study on environmental problems, specifically on Brownfield redevelopment. After an introductory part with definitions and a general framework, the paper presents the ideas of environmental economics, free market environmentalism, institutional economics, and ecological economics. Each part is complemented by an overview of empirical research on the field of historical contamination. The last part shows two particular cases in the Czech Republic, where the ecological economics approach has been applied for the assessment of economic effectiveness of remedial processes.

Keywords: Brownfields, cost-effectiveness, ecological economics, economic theory, environmental economics, free market environmentalism, historical contamination, institutional economics, remedial targets.
\end{abstract}

\section{INTRODUCTION}

Since the end of the 1980s, the Czech Republic has been facing the problem of cleaning-up the ecological burden of the past military and mining activities of the former socialistic regime. These types of Brownfields are mainly abandoned buildings, areas, and dangerous deposits available for re-use. The original polluter is responsible for the cleaning-up of these localities under government legislation [1].

The problem of Brownfields revitalization is relatively new in the Czech Republic. Mapping of the rest of Brownfields is done by two subjects: Czech Invest (agency for the support of business and investments in the Czech Republic, under the administration of the Ministry of Industry and Commerce) and the Ministry for Regional Development. Czech Invest is in charge of larger localities with a clear investment potential (about 2 hectares). The Ministry for Regional Development mainly focuses on industrial Brownfields less attractive for larger investments, but more adequate for smaller business and for the cooperation between the private and the public sectors [1].

This work gives an overview of the different economic approaches to remediation management with some examples of their application worldwide and shows two concrete case studies in the Czech Republic, where the ecological economics approach have been practically applied. Both these cases have been part of the work pursued by the Institute of Novel Technologies and Applied Informatics, Technical University in Liberec, Czech Republic with the technical support of a private company. For the purposes of this work, we named it Company A. 


\section{ECONOMIC APPROACHES TO THE ANALYSIS OF REMEDIAL PROCESSES}

\subsection{Environmental economics}

According to this discipline, environmental problems appear due to the existence of market failures and externalities.

The analysis of externalities and distribution of resources are based on economic and quantitative terms, as function of prices, costs, and monetary benefits. These types of analyses also suggest the application of tools in order to regulate the disbalance between nature and economy.

The traditional instruments for environmental regulation recommended by environmental economists tend to indicate 'command and control' measures such as environmental regulations, and the application of taxes and tariffs on pollution, originally based on the analysis of welfare economics of negative externalities by Pigou [2].

According to the neoclassical approach, environmental problems should be solved at a level that allows the maximum benefit at the least amount of abatement costs. Economically speaking, the 'efficient' level of pollution is recognized at the point at which marginal damages equal marginal abatement costs. Figure 1 illustrates the neoclassical concept of pollution level efficiency. The optimal pollution level is denoted by point $O P$, where marginal abatement costs equal marginal damage expressed in terms of monetary units.

Neoclassical economics deals with this issue with tools approaching monetary values to nonmarket goods. The methodologies used for these estimations in the branch of Brownfields can vary from benefit transfer methods to non-market valuation methods such as hedonic pricing, and contingency valuation among others.

\subsection{Free market environmentalism}

Some authors reject the government intervention in environmental issues because of the fundamental reason that this kind of intervention may not reflect a transparent compromise toward the environmental protection. On the contrary, the forces of market and free decision-making processes

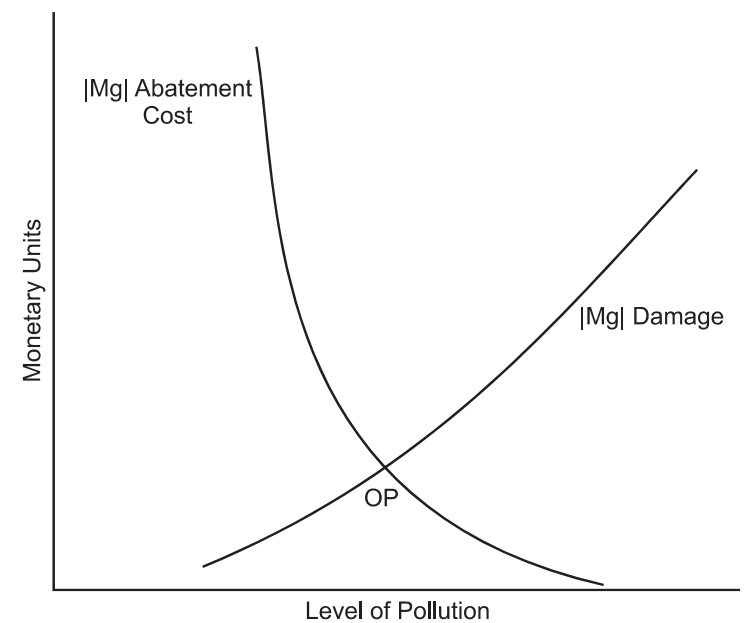

Figure 1: Optimal level of pollution. Environmental economics perspective [3]. 
could present better results for the individuals including the environment and even achieving more effective forms of protection of the nature.

Free market environmentalism has adopted the basic idea of the Austrian School of Economics, whose main representative Hajek [4] claims that government intervention may limit freedom, which could become dangerous for the natural development of human principles in democratic societies.

Free market environmentalism does not support the idea of interventionism through taxation or any kind of environmental regulation. The solution to environmental problems should be left in the hands of a well-designed system of property rights.

The trend of a centralized treatment of environmental issues around the management of Brownfields has attracted the attention of representatives of free market environmentalism.

Empirical studies encourage the implementation of free market tools in order to achieve the solution of certain environmental problems.

The criticism and skepticism toward the efficiency of the U.S. Superfund is one of the clearest and more recent examples of the disagreement of government interventionism within the framework of cleaning-up processes and restoration of Brownfields.

Shawn [5] has defined the U.S. Brownfields legislation as 'take away states' freedom to cleaning-up sites to their specifications'. Stroup and Townsend [6] criticized the great amount of transaction costs and thus, the evident inefficiency of the Comprehensive Environmental Response, Compensation, and Liability Act (CERCLA) in achieving its original goals. They argued that the main weakness of the program was its general and global character. The inefficiency issue has not been solved even with the attempt to lessen transaction costs with the reduction of bureaucracy through the introduction of more flexible rules for budgetary reports and controls. In other words, according to the authors, federal laws have a strong potential for corruption and are not able to solve local and specific problems related to contaminated sites. Thirteen years after, Mailman [7] presented another mechanism out of the free market framework: the U.S. bankruptcy code. The author described it as one of the threats for the Superfund's effectiveness in achieving its goals. According to the American Society of Civil Engineers (ASCE) and its study called the 'Report Card for America's Infrastructure', the rate of Superfund site clean-up improved until 2003, but it has not been able to keep up with the rate at which new and potential sites are identified.

Nugent [8] presented alternative ways to the development of Brownfields. His innovative idea of 'cleaning soil with mushrooms' suggested that there can always be an alternative to the management of environmental goods. According to the author, it is not feasible (and also not necessary) to cleanup completely one site or all the contaminated sites, as per the Environment Protection Agency's (EPA) policy. Therefore, one may look for attractive economic activities that will motivate people to cooperate and find practical solutions and clear results for the individuals affected. Nugent said that his company can gain a profit while using environmentally friendly technology on residential properties or former military sites.

\subsection{New institutional economics}

The research of new institutional economics (NIE) has partially started as a reaction to welfare and mainstream economics, mainly to Pigou's conception of externalities [9]. Thanks to the concepts of Coase [10], NIE acknowledges the existence of transaction costs (or costs incurred in making an economic exchange) and their influence on economic and environmental outcomes. Instead of the idea of externalities, which Paavola and Adger [11] considered as a narrow concept, NIE is characterized by the broader concept of interdependence. 
The application of NIE in Brownfield management can be perceived through studies that observe and evaluate the institutional framework within specific locations. Brownfield management initiatives correspond traditionally to centralized decisions from different legislative frameworks. The cases presented below mainly focus on the analysis of governance characteristics and information issues.

The case presented by Williams and Dair [12] reflects how general policies are not able to 'encourage' companies to achieve 'general goals'. The observations made by the authors conclude that the limitations regarding the sustainability of Brownfield development correspond mainly to characteristics of stakeholders' participation.

Meyer and Estrin [13] applied a combination of resource-based and transaction-cost theories in order to analyze three market entry modes for firms considering expansion strategies: conventional acquisitions, greenfields, and Brownfields. The authors identified Brownfields as a hybrid mode of acquisition and found after observation of various studies that firms tend to choose the acquisition of Brownfield if it can provide them already established local assets which can be combined with their competencies.

\subsection{Ecological economics}

Ecological economics is a discipline whose origins correspond mainly to the reaction to the ideas of environmental economics. Ecological economics rejects the concept of the natural environment only by means of its use and opts for values for the human beings and thus, considers it necessary to include human needs in the evaluation and management of ecosystem. It is focused on the intrinsic value of nature and therefore, has an ecocentric approach. According to Costanza et al. [14], the objectives of study of this discipline are a wider understanding of the complex interrelationships between the economic, the social, and the environmental systems in order to find solutions to conflicts existing within these systems.

Different from free market environmentalism, ecological economics believes in the power of centralized environmental policy, which can support programs toward achieving the maximum protection of environmental amenities according to limits set by natural scientists. The evaluation of such actions will be developed mainly under the results of cost-effectiveness analysis. A cost-effectiveness analysis is able to show the ratio at which money expenditures are related to expected results for specific areas. In other words, ecological economics might develop studies trying to find the cheapest way of how to get the desired environmental target.

The empirical work of ecological economics in the branch of Brownfields includes quality assessments for projects concerning urban planning [15] or applications of specific systems such as GIS (geograhical information solutions) [16], suggesting wider approaches for natural valuation than the neoclassical ones (Hedonic Pricing).

Another close approach to the analysis of ecological economics in the Brownfield area can be found in studies concerning the application of industrial ecology.

\subsubsection{Cost-effectiveness analysis for remedial processes}

For the analysis of the economic effectiveness of remedial processes, it's necessary to understand the 'effect' as an interaction of inputs and outputs [17]. The idea behind this is to find the possibility of minimalization of costs and/or the maximalization of the utility of the remedial process.

On the one hand, it is necessary to analyze the costs (outputs) of the clean-up process and on the other hand to define its outputs. The results can be presented as a ratio of cost intensity (input/output), or as a ratio of cost-effectiveness (output/input). 
A reasonable parameter for the output's specification might be the actual amount of removed pollutants (in physical units, e.g. tons). A relevant output of the remedial process can be also defined as the expected target parameters (pollution level). The costs (inputs) of each remedial technology would be consequently confronted with the targets in order to know the cost-effectiveness of a concrete technology.

The approach based on cost-effectiveness is practically recognized to be more adequate. Various alternatives for the technology methods with the highest cost-effectiveness rate can be formulated. The optimalization criteria can be the maximization of the positive effects for each unit of incurred costs, or the minimalization of costs for each unit of acquired positive effect.

For a qualified cost-effectiveness assessment of a clean-up process, it is necessary to not only know the costs and define outputs (the effects, or commonly the target parameters), but it is also important to take into account the risks. The risk factors depend on the right selection of the remedial technology, on the right decision about the limitation or interruption of activities related to the remedial locality, and also on the approach of institutions, legislation, and stakeholder's interest on the clean-up process [14].

The process of selection of the optimal remedial technology is time-consuming. It starts from roof estimations and comes gradually to more precise results. The first information about the most important variables (mainly costs and remedial risks) is available just in a limited way and comes from the pre-cleaning-up exploration in the area. In the first phase, it is necessary to quantify the damages that resulted from old environmental burdens of the past.

In a traditional economic environment, there are many tools for quantifications (price information, company's cost system related to the production, calculations of risks for specific branches, etc.). However, remedial processes reveal just limited information about the contamination and the risks related to it. The introductory phase (estimation of the preliminary budgets) is mainly based on hypothesis and empirical estimations.

The elaboration of estimations and costs structures in this phase becomes extremely complicated due to the lack of enough data. Generally, the costs are estimated according to the presence of significant volumes of pollutants in certain locality, which leads to a less objective increase of costs [14]. After the acceptance of the remedial measures (and with that also the acceptance of the budget), it is necessary to clearly define the remedial target, resp. the remedial effect (target clean-up parameters). This depends mainly on the demands of relevant institutions and concrete stakeholders.

After the collection and analysis of relevant data, the basic platform for the ecological and economic acceptable solution in accordance with the risks rate is created.

After the selection of the optimal alternative, it is necessary to specify data about the incurred costs during the different steps of the remedial activity. The obtained data can be very useful for future applications, for statistical analysis, for the modification of the remedial method, and for costeffectiveness assessments.

\section{CASE STUDIES}

The following case studies illustrate the assessment of the revitalization of effectiveness for two concrete examples from the Czech Republic.

Both cases are an example of the approach of ecological economics.

The second case shows particularly how a remedial alternative can be selected through the optimization of inputs, outputs, and potential risks.

\subsection{Case Pisecna}

The specific case for this part of the work is the locality Pisecna, which served as a deposit of industrial residuals for the state company OEZ Letohrad during the 1970s. The former quarry had direct 
contact to galvanic sediments which contained a huge amount of heavy metals and chloride hydrocarbons that were gradually starting to infiltrate into groundwater.

The site is located in an important drinking water catchment area, and that is why the research works started already at the end of the 1980s.

Research and monitoring continued for the next few years due to the geological and hydrogeological characteristics of the site combined with the concentration of pollutants found in the exploration wells. In 1997, the clean-up of the deposit with the complete extraction of the contaminant soils was pursued. The groundwater clean-up was started in the year 2004 [18].

In collaboration with the COMPANY A, we pursued a pilot test for the application of nanoiron particles in the locality within the research of the project activities. From the technical point of view, it was a simple application as for the injection into the subsoil common hydrogeological wells were used.

The nanoparticles were introduced through mixing tubes to the water flow after its treatment through filtration focused on the elimination of oxidation.

A nanoiron suspension was prepared according to the local particular conditions. The suspension was applied directly to the affected zones through 30 wells. The specification of the parameters of the applied methods is shown in Table 1.

For the location Pisecna, the concentration of nanoparticles determined by laboratory tests was between 1 and $3 \mathrm{~g}$ of iron/liter of polluted water influencing the subsoil. For this location, about $500 \mathrm{~m}^{3}$ of polluted groundwater was estimated.

Based on laboratory tests, the consumption of nanoiron was estimated to be about $1000-1500 \mathrm{~kg}$.

The injection was pursued at all the wells, at the same time the pumping of water from selected wells was also done (see Fig. 2).

It is still early to present a complete economic evaluation of this case, however, we made an effort to show the economic characteristics of the cleaning-up process in Table 2.

From the information shown in Table 2, we can easily observe that $1 \mathrm{~kg}$ of removed pollution costs 360 EUR. From the technical point of view, nanoiron is a very effective way to decontaminate groundwater and subsoil, however, it is not so often applied due to its high price (72-108 EUR/kg). At the present time, the commercial supply of nanoparticles is low and one also needs to take into account the costs of research. Some research centers in the Czech Republic are working on developing this product with recycled materials, which could give an opportunity to lower the clean-up costs.

Table 1: Parameters specification for the nanoiron infiltration.

\begin{tabular}{lcc}
\hline Year & 2009 & 2010 \\
\hline Wells & 30 & 20 \\
Area $\left(\mathrm{m}^{2}\right)$ & 1200 & 800 \\
Collector $(\mathrm{m})$ & 10 & 10 \\
Subsoil volume $\left(\mathrm{m}^{3}\right)$ & 12000 & 8000 \\
Nanoparticles $(\mathrm{kg})$ & 370 & 200 \\
Suspension $(\mathrm{kg})$ & 1850 & 1000 \\
Water used $\left(\mathrm{m}^{3}\right)$ & $135-270$ & $100-200$ \\
Estimated absorption time & $1-2$ months & $1-2$ months \\
\hline
\end{tabular}




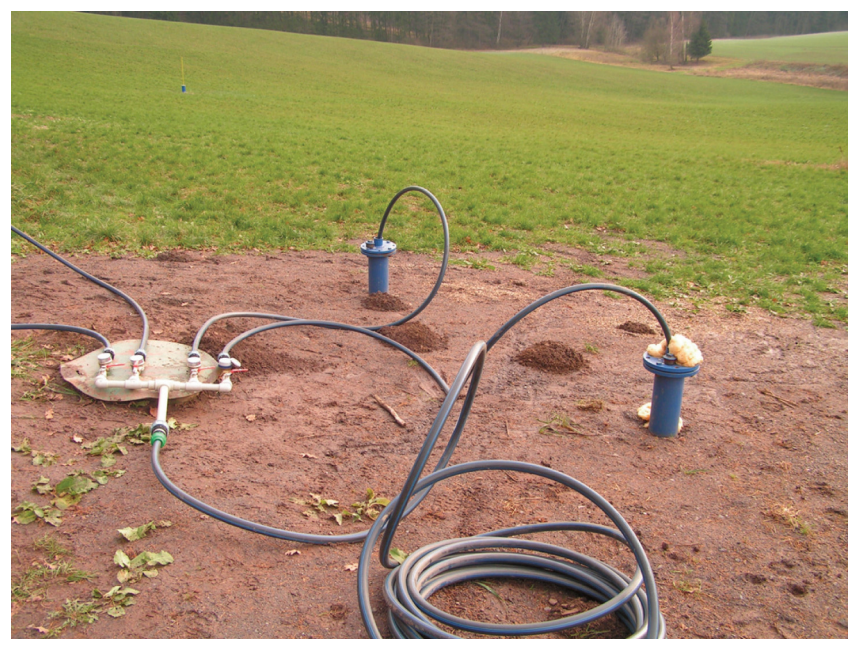

Figure 2: Well network - Pisecna, internal materials company, Company A.

Table 2: Cost information, clean-up process of Pisecna.

\begin{tabular}{lc}
\hline $\begin{array}{l}\text { Volume of removed } \\
\text { contamination }\end{array}$ & $1 \mathrm{t}$ \\
\hline Clean-up area & $2000 \mathrm{~m}^{3}$ \\
Used nanoiron & $1.3 \mathrm{ton}$ \\
Total cost for nanoiron & $140000 \mathrm{EUR}$ \\
Total cost for wells & $60000 \mathrm{EUR}$ \\
Other costs & $40000 \mathrm{EUR}$ \\
Monitoring & 120000 EUR \\
Total clean-up cost & 360000 EUR \\
\hline
\end{tabular}

\subsection{Case Spolchemie}

The aim of the clean-up process for this case has been to reduce the risk of the negative influence into the environment due to the existence of dangerous materials as a consequence of the activities of the company 'Spolchemie' in Usti nad Labem (northwestern part of the Czech territory) (Fig. 3).

The chemical plant Spolchemie is located in the center of regional capital city Usti nad Labem. In the company's area, there were problematic chemical operations due to the production of 'Ledons', which are freons known to cause damage to the ozone layer. The production of Ledons took place from the middle of the 1960s. From year 1986, it was limited due to the regulations of the Montreal Protocol. In 1996, the production of freons was terminated. From year 1996 until 2001, non-used freons were recycled by the same company (approximately 165,000 tons of freons were regenerated). The company operated for about 30 years [18].

The production capacity of Ledons was 1800 ton/year. For the production of 1 ton of Ledons, it was necessary to use 1.3 tons of carbon tetrachloride, which makes approximately 70,000 tons in 12 years of operation. Carbon tetrachloride was stored in different areas of the company. Not only 


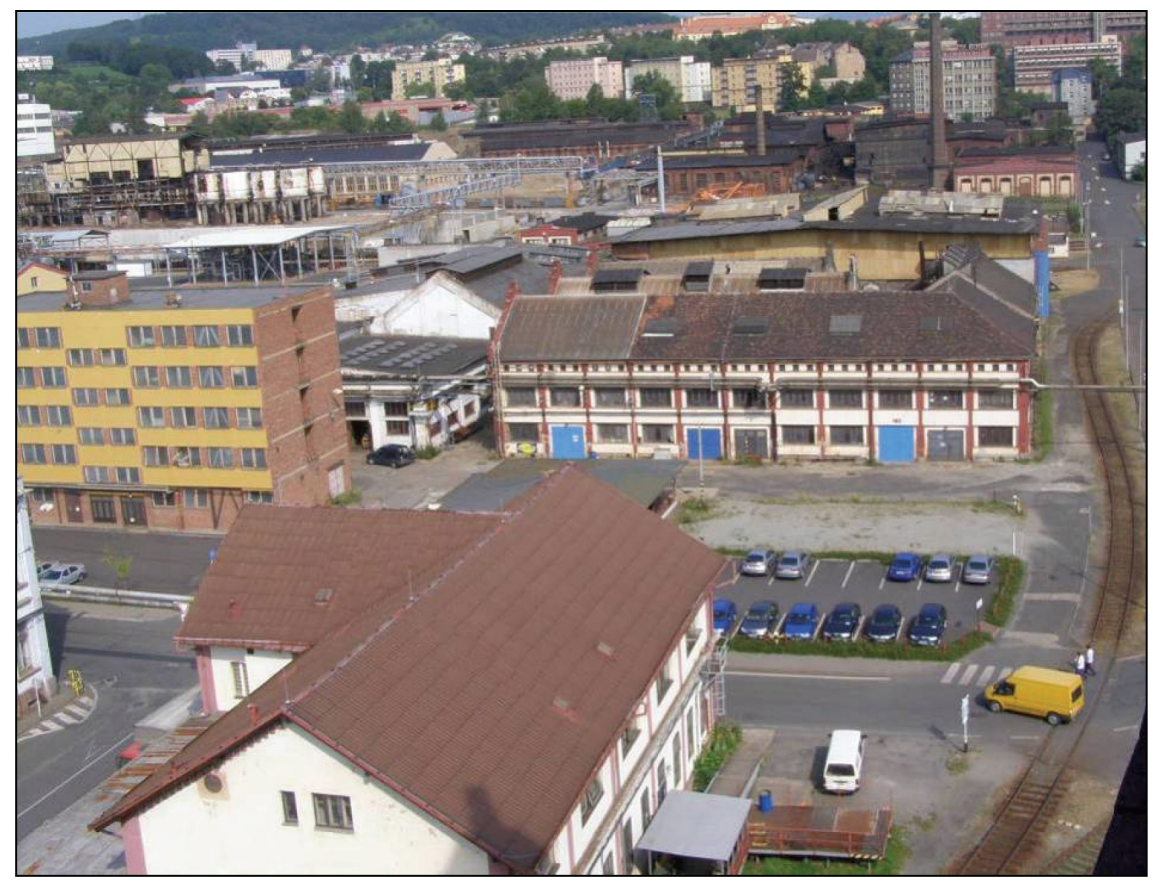

Figure 3: View of the former company Spolchemie.

the non-ecological way of production of Ledons, but also the inadequate treatment of this problematic material led to the spread of the contamination. The company, Company A identified three possibilities of remedial technologies based on pre-cleaning-up testings, which are discussed in the following sections.

\subsubsection{In situ oxidation through potassium permanganate}

The principle of this method is to add enough quantity of oxidation reagent to the polluted area, in order to achieve an adequate dissolution of the organic materials in the clean-up area. This method allows to achieve a relatively successful decrement of the concentration of the toxic materials in groundwater and subsoil [19]. This reagent was easily obtained because it was produced directly by Spolchemie. One disadvantage of this method is the fact that the reagent might not be completely effective in some specific non-permeable polluted areas.

\subsubsection{In situ oxidation through Fenton's reaction in combination with venting}

The principle of this method is basically the same as the first method mentioned above. Just the reagent is different. This method also allows to achieve a relatively successful decrement of the concentration of the toxic materials in groundwater and subsoil. The advantage of this method is its double effect [19]. During oxidation, the subsoil gets heated, which increments the effects of the remedial method. On the other hand, there is still little experience with the application of the method. Another disadvantage is the difficulty of the oxidant reagent's transport in heterogeneous environment. A big complication is also the relatively great quantity of gases originated during the dissolution of hydrogen peroxide. 
3.2.3 Controlled steaming in combination with venting

The increment of the subsoil's temperature helps to achieve a faster mobilization for a consequent extraction of the contamination through a system of wells on the surface. The method also enables to lower absolutely and without limitation the concentration of pollutants in the pumped water and from the subsoil.

The advantage of this method is the relatively fast remedial process and great effectiveness of the system. In comparison with the previous two methods, this method doesn't present the problem with heterogenous environments. It can also cover greater areas [19]. However, there is just few information about the effectiveness of the method for specific forms of pollution, which increments the level of uncertainty. After researching the effectiveness of each technology, the costs for each technology were also estimated. We divided them into three groups: A, B, and C.

The first part 'Work Preparation' contains research and project working, pre-cleaning-up monitoring, building site arrangement project, supply, and technology installation. The second part 'Operation Costs' refers to the realization of the concrete remedial technology. It covers mainly all the costs related to the installation of the well system: well excavation (according to the diameter and the soil type), well cleaning, well armature (according to material and the well diameter), well top and well cover (according to the used materials), pump-up costs (according to the type), and other costs. Part of the calculation is also the reagent consumption. The third part 'Final Works' contains post-clean-up monitoring, project activities related to the end of the remediation, building site liquidation, and technology disassembling. Tables 3-5 show the costs with more detail.

Table 3: Estimated costs. Option 1.

\begin{tabular}{lc}
\hline Item & EUR (without VAT) \\
\hline A - Preparation works & 126676,00 \\
B - Operation costs & 34282,40 \\
C - Final works & 54894,00 \\
& 0 \\
Total & 215852,40 \\
Provision (10\%) & 21585,24 \\
& 0 \\
Total with provision & 237437,64 \\
\hline
\end{tabular}

Table 4: Estimated Costs. Option 2.

\begin{tabular}{lc}
\hline Item & EUR (without VAT) \\
\hline A - Preparation works & 255476,00 \\
B - Operation costs & 113234,00 \\
C - Final works & 65113,60 \\
& 0 \\
Total & 433823,60 \\
Provision (10\%) & 43382,36 \\
& 0 \\
Total with provision & 477205,96 \\
\hline
\end{tabular}


Table 5: Estimated Costs. Option 3.

\begin{tabular}{lc}
\hline Item & EUR (without VAT) \\
\hline A - Preparation works & 313244,00 \\
B - Operation costs & 310615,60 \\
C - Final works & 136108,80 \\
& 0 \\
Total & 759968,40 \\
Provision (10\%) & 75996,84 \\
& 0 \\
Total with provision & 835965,24 \\
\hline
\end{tabular}

\subsubsection{Selection of the optimal remedial option}

For the assessment of the adequate remedial option, a more elaborated model was defined to take into account the risks of failure for each technology, its effectiveness, and economic aspects.

$$
\text { Feasibility of the technology }=\frac{E+C}{R}
$$

where $E$ is the remedial effect (rate of fulfillment of the target parameters); $C$ is the cost; and $R$ is the failure risk rate [20].

An assessment of cost, risk, and potential effect (1-3 points) for each possible applicable technology was pursued.

The above-mentioned elaborated cost assessment can be summarized through the scale shown in Table 6 . The highest cost was assumed to be 'problematic' and was given 1 point, the least cost was given 3 points.

From the above information, we can easily infer that the best option from the point of view of costs is the technology using potassium permanganate.

Table 7 summarizes the factors for the estimation of the risk rate.

Table 8 shows the results for each technology taking into account the factors for the risk assessment.

In the above two case studies, three technologies were compared. The first method was tested several times, the effectiveness of the method for specific environments is known. This method doesn't have practically any influence in the company's operations. The same is true for other technologies, as a good knowledge of the Czech environmental legislation is necessary. The other two methods are new and have not yet been safely tested. The possibility of their influence in the company's operations cannot be excluded. The remedial effect has been evaluated through the effectiveness of the technology and the certainty of fulfillment of the target parameters (Table 9).

All technologies got 4 points in this assessment due to the fact that both effectiveness and fulfillment certainty were at a good level. Table 10 summarizes the results of all the assessments for the three technologies observed.

The first option selected was the optimal remedial technology: oxidation through potassium permanganate. This option is less costly (two to four times lower cost than the other options). The last two options were more energy demanding due to the venting. Even if the effectiveness assessment showed the same levels for the three technologies, there was also the risk management which presented higher values for the first option, mainly because of the fact that the other technologies are still new and not enough proven. 
Table 6: Cost assessment for each remedial option.

\begin{tabular}{lc}
\hline Option & Costs - Points \\
\hline 1 & 3 \\
2 & 2 \\
3 & 1 \\
\hline
\end{tabular}

Table 7: Parameters for the risk assessment.

\begin{tabular}{|c|c|c|c|}
\hline Risk $R$ & Low & Medium & High \\
\hline Points & 1 & 2 & 3 \\
\hline Applied technology & Standard & Proved & New \\
\hline Operation & $\begin{array}{l}\text { Small effect to the } \\
\text { company's operations }\end{array}$ & $\begin{array}{l}\text { Possible effects to the } \\
\text { company's operations }\end{array}$ & $\begin{array}{l}\text { Considerable effect to the } \\
\text { company's operations }\end{array}$ \\
\hline Legislation & $\begin{array}{l}\text { Without permits and } \\
\text { other legal documents }\end{array}$ & $\begin{array}{l}\text { With standard permits } \\
\text { and other legal docu- } \\
\text { ments }\end{array}$ & $\begin{array}{l}\text { Exceptions or special } \\
\text { legal documents }\end{array}$ \\
\hline
\end{tabular}

Table 8: Risk Assessment for each remedial technology.

\begin{tabular}{lcccc}
\hline Option & Technology & Operation & Legislation & Total \\
\hline 1 & 1 & 1 & 3 & 5 \\
2 & 2 & 2 & 3 & 7 \\
3 & 2 & 2 & 2 & 6 \\
\hline
\end{tabular}

Table 9: Parameters for the effectiveness assessment.

\begin{tabular}{|c|c|c|c|}
\hline Evaluation & Low effect & Intermediate effect & High effect \\
\hline Points & 1 & 2 & 3 \\
\hline $\begin{array}{l}\text { Certainty of fulfill- } \\
\text { ment of the target } \\
\text { parameters }\end{array}$ & $\begin{array}{l}\text { Fulfillment of the } \\
\text { target parameters } \\
\text { very problematic }\end{array}$ & $\begin{array}{l}\text { Fulfillment of the } \\
\text { target parameters, } \\
\text { however, the appear- } \\
\text { ance of residual } \\
\text { pollution cannot } \\
\text { be excluded }\end{array}$ & $\begin{array}{l}\text { Fulfillment of the target } \\
\text { parameters, without } \\
\text { limitations }\end{array}$ \\
\hline $\begin{array}{l}\text { Remedial } \\
\text { effectiveness }\end{array}$ & $\begin{array}{l}\text { Low pollution } \\
\text { reduction }\end{array}$ & $\begin{array}{l}\text { Intermediate } \\
\text { pollution reduction }\end{array}$ & High pollution reduction \\
\hline
\end{tabular}


Table 10: Selection of the optimal remedial technology.

\begin{tabular}{lccccc}
\hline & & & & $\frac{E+C}{}$ & \\
Option & $R$ (risk) & $E$ (effect) & $C$ (costs) & $R$ & Position \\
\hline 1 & 5 & 4 & 3 & 1.40 & 1 \\
2 & 7 & 4 & 2 & 0.86 & 2 \\
3 & 6 & 4 & 1 & 0.83 & 3 \\
\hline
\end{tabular}

The clean-up methods for both polluted subsoil and groundwater were mainly based on the pumping-up of water or suction of soil air (venting) with a consequent decontamination (ex situ methods).

It was not until the last years that methods based on other principles started to be tested, verified, used, and optimalized in the Czech Republic.

These methods can be classified based on the absorbtion of specific pollutant chemicals or compounds with the aim of changing the biological materials into non-pollutants or less toxic materials.

One of the most important groups of these methods are oxido-reductive ones based on the changes of the oxidant state of the pollutants. This leads to a pollution reduction. In this part of our work, we presented an application of the method of chemical reduction of pollutants with the utilization of elementary iron in the form of nanoparticles. This method seems to be more effective from the economic point of view (taking into account the quantity of eliminated pollutants/value of clean-up intervention).

\section{CONCLUSIONS}

The assessment of economic effectiveness of remedial processes is a very difficult discipline. It is not possible to create one single model, which can assess whether the resources used in certain locality have been optimally managed in order to revitalize it. The decision-making process within the management of Brownfields is followed by a certain level of risks and multi-criteria decision making with different costs and environmental utilities (the last extremely difficult to express into monetary terms). For concrete localities, the environmental utility is defined through the target remedial parameters expected by the submitter (expected level of pollution, the defined concentration of remedial limits, etc.). The clean-up area and the remedial method(s) are selected after assessing the potential interactions of pollution with the subsoil and the surroundings.

Clean-up projects that are meant to be used for the revitalization of depressed zones are mainly particular because of the uncertainty related to the quality and dimension of the research pursued about the pollution at the subsoil area. This leads to a constant actualization of documentation (it becomes necessary to react to new findings). Last but not least is the planning of future utilities for the area in question (this concept and other kinds of soft data are unfortunately ignored under the Czech Republic Brownfields management program).

Companies in charge of remedial processes have to understand, besides the common economic legislation, the legislation related to the protection of the environment among others.

One can identify notable differences in the application of economic theory toward the management of Brownfields, depending on specific schools of thought. Neoclassical economics through the study of environmental economics focuses on the utilitarian approach and tends to promote the use of command and control measures in order to achieve the 'pollution optimum'. Free market environmentalism does not support the government interventionism and suggests, on the other hand, market-oriented solutions reflecting the freedom of decisions made by affected stakeholders. NIE makes assessments of the 
success of institutional arrangements toward the resolution of environmental conflicts among affected parties. Ecological economics underlines the importance of a multidisciplinary and global approach in order to achieve not only economically efficient solutions, but also ecologically effective ones.

The above-presented cases from the Czech Republic indicate the possible approaches to the resolution of remedial processes in depressed areas and present an extension of our theoretical-empirical work published before [21].

The cases discussed here can be analyzed under the perspective of ecological economics since the resolution of the cleaning-up process is oriented to test an effective method from the technological point of view. A broader concept of economic efficiency for the cases was not taken into account.

Our suggestion is to follow a wider scheme of decision making for the management of historical contamination, particularly for the Czech Republic which involves the constant evaluation of objectives and the interests of different stakeholders [22].

A great part of large cleaning processes in the Czech Republic was decided by a government decree and has to be pursued by the state companies which had in charge the pollutant activity (if they can be identified). This decree is related to military and mining activities during the socialistic time. It is reasonable to apply a method which can successfully eliminate effects of pollution, but on the other hand, it is also recommendable to try to understand the problems in a wider perspective that can include more scenarios to follow. This can be achieved by the application of diverse tools involving more than just one type of economic analysis.

\section{ACKNOWLEDGMENTS}

This article was created under the state subsidy of the Czech Republic within the research and development project ‘Advanced Remediation Technologies and Processes Center' 1M0554 - Program of Research Centers supported by Ministry of Education.

\section{REFERENCES}

[1] Zizka, M.. Rydvalova A.P., Ekonomické souvislosti revitalizace Brownfields. 1. vyd. Praha: nakladatelství Oeconomica, roč. 54, č. 5, s. pp. 632-645, 2006.

[2] Pigou, A.C., The Economics of Welfare, London: Macmillan, p. 976, 1920.

[3] Sauer P.Ekonomické souvislosti řešení ekologických důsledků pobytu sovetských vojsk na našem území, Acta Oeconomica Pragensia, č.2/1993.

[4] Hajek, F., The Fatal Conceit: The Errors of Socialism. Routledge: London, pp. 194, 1989. ISBN 978-0226320663.

[5] Shawn, J.S., Not Quite A Gentleman. The Environmental Forum. The Environmental Law Institute, Washington, D.C. 2003. ISSN 0731-5732.

[6] Stroup, R. \& Townsend B., EPA's New Superfund Rule: Making the Problem Worse. Regulation: The Cato Review of Business \& Government, Washington, D.C., 3, 1993.

[7] Mailman, R., Cleaning Up Its Act: Improving CERCLA Efficiency within the Bankruptcy Code. 27 Whittier Law Review. Whittier CA, 27(2), pp. 557-596, 2005. ISSN 0195-7643.

[8] Nugent, S., Mushrooms Meet Brownfields. A Market for Fungal Remediation. PERC Reports. 24(4). Washington DC 2006. Online http://www.perc.org/articles/article847.php

[9] Coase, R., The Problem of Social Cost. Journal of Law and Economics, III, pp. 1-44, 1960. ISSN 00222186.

[10] Coase, R., The nature of the firm. Economica, IV, pp. 386-405, 1937.1920. ISSN 0013-0427.

[11] Paavola J. \& Adger N., New Institutional Economics and the Environment: Conceptual Foundations and Policy Implications. CSERGE Working Paper. University of East Anglia, Norwich 2002. Online http://www.uea.ac.uk/env/cserge/pub/wp/edm/edm_2002_06.pdf 
[12] Williams, K. \& Dair C., Five barriers to sustainable Brownfield development. Town and Country Planning, 72(11), pp. 344-345, 2003. ISSN 0040-9960.

[13] Meyer, K. \& Estrin, S., Brownfield entry in emerging markets. Journal of International Business Studies. Palgrave. Hampshire, 32(3), pp. 575-584, 2001. ISSN 0047-2506.

[14] Costanza, R., Cumberland J., Daly H., Goodland R. \& Norgaard R., An Introduction to Ecological Economic (Hardcover) CRC Press. Boca Raton: Florida, p. 275, 1997.

[15] Nijkamp, P. \& Rodenburg, A., Success factors for sustainable urban brownfield development: A comparative case study approach to polluted sites. Ecological Economics, 40, pp. 235-252, 2002. ISSN 0921-8009.

[16] Geoghegan, J., Wainger, L. \& Bockstael, N., Spatial landscape indices in a hedonic framework: an ecological economics analysis using GIS. Ecological Economics, 23(3), pp. 251-264, 1997. ISSN 0921-8009.

[17] Mateju,V. \& kol, A., Kompendium sanačních technologií. Vodní zdroje Ekomonitor, s.r.o. Chrudim, 2006. ISBN 80-86832-15-5.

[18] Drechsmann, P.,:Anforderungen an eine Sanierungsuntersuchungunter Berücksichtigung von Nutzen-Kosten-Aspekten, Im Auftrag des Landesumweltamtes Nordrhein-Westfalen, Essen 2000[online]. 2009. [cit 2010-11-10]. URL: <http://www.lanuv.nrw.de/veroeffentlichungen/ malbo/malbo11_web.pdf>

[19] Internal materials Company A, 2009.

[20] Kvapil, P. \& kol, A, Technicko-ekonomická studie mraku Internal materials Aquatest, 5, 2009.

[21] Cihakova Aguilar, S., Cernikova, M. \& Dubova, M., Historical contamination and brownfield management: what does economic theory say about it? Ecosystems and Sustainable Development VIII. WIT Press. Southampton, pp. 239-252, 2011. ISBN 978-1-84564-510-6.

[22] Cihakova Aguilar, S., Decision making and brownfield management. Ekonomie a Management $E+M .3 / 2009$, pp. 19-33. ISSN 1212-3609. 